No. $14(18)$

2017

\title{
RAZ JESZCZE O CZTERECH BARWACH
}

\begin{abstract}
Antoni Smoluk
Streszczenie: W pracy dowodzi się twierdzenia o czterech barwach. Korzysta się z pojęcia produktu map i minimalnych kolorowań.
\end{abstract}

Słowa kluczowe: minimalne kolorowanie, pierścień rozcinający, produkt map.

JEL Classification: C02, C69

DOI: $10.15611 / \mathrm{dm} .2017 .14 .05$

Celem nauki jest poznanie świata, doskonalenie człowieka i perfekcja formalna. Mając to na uwadze, raz jeszcze przepowiem, uproszczę i jednocześnie uszczegółowię wcześniej podany dowód twierdzenia o czterech barwach [Smoluk 2016; 2017]. A ponadto zawsze trzeba pamiętać, iż repetitio est mater studiorum. Mapy są jednym z ważniejszych sposobów wizualizacji danych statystycznych. Mapy naturalnie interesują geografów, demografów, językoznawców, klimatologów, biologów itd. Jednym słowem, żyjemy w świecie map, stąd sądzę, że twierdzenie o czterech barwach zaciekawi wszystkich. Mapę można traktować jako powierzchnię wielościanu. Wieloboki są krajami albo państwami, krawędzie wieloboków są granicami, a punkty, w których się stykają trzy lub więcej wieloboków, są wierzchołkami mapy. Wierzchołek jest parzysty, gdy styka się w nim parzysta liczba państw, a nieparzysty w przeciwnym razie. W dalszym ciągu zamiast wielościanów będziemy mówić o mapach na sferze. Są to oczywiście mapy płaskie, bo uzwarcona jednym punktem płaszczyzna jest sferą. Na załączonych rysunkach (rys. 2, 6, 7, 8 i 11, 12, 13, 14, 15) zewnętrzny okrąg należy zawsze ściągnąć do punktu tak, aby powstała mapa na sferze; ten punkt jest wierzchołkiem tylko wtedy, gdy na zewnętrznym okręgu leżą wierzchołki. Państwa sąsiednie to takie, które mają wspólną krawędź; jeśli mają tylko wspólny wierzchołek, a nie mają wspólnej granicy, to nie są krajami sąsiednimi. Kolorowaniem mapy nazywa się takie barwienie wieloboków, przy którym

\footnotetext{
Antoni Smoluk

Wrocław University of Economics

email: math@ue.wroc.pl

ORCID: 0000-0002-9990-037X
} 
państwa sąsiednie mają różne kolory; jest to kolorowanie zgodne. Liczbą chromatyczną mapy jest najmniejsza liczba kolorów wystarczająca do jej zgodnego pokolorowania. Hipoteza Francisa Guthriego z 1852 roku (vide Internet) mówi, że do zgodnego pokolorowania dowolnej mapy płaskiej potrzeba nie więcej niż cztery barwy. Hipotezę tę rozstrzygnięto pozytywnie w 1976 roku [Appel, Haken 1976]. Istotnie do zgodnego pokolorowania każdej mapy płaskiej wystarczają cztery barwy. Autorów dowodu twierdzenia o czterech barwach z 1972 roku wspomaga komputer.

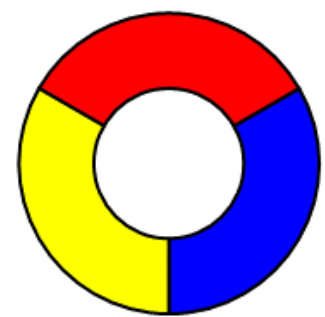

Rys. 1. Pas rozcinający z trzech krajów

Źródło: opracowanie własne.

W artykule proponuje się nowy, prosty i krótki dowód tego twierdzenia bez komputerowych weryfikacji. Wołami roboczymi dowodu są dwa pojęcia: pierwszym z nich jest iloczyn map, a drugim minimalne kolorowanie. Iloczyn, czyli produkt map, jest zabiegiem sprowadzającym kolorowanie mapy do niezależnego barwienia dwóch map mniejszych.

Mapa złożona z jednego kraju, czyli sfera, mapa złożona z dwóch krajów, czyli sfera podzielona na dwie części, oraz mapa złożona z trzech krajów, czyli sfera podzielona na trzy pasy południkowe, to elementy neutralne przy mnożeniu map. Jeżeli na mapie istnieje pas złożony z jednego kraju (rys. 9) albo dwóch krajów (rys. 10), albo trzech krajów (rys. 1, 3, 4 i 5), rozcinający sferę na dwa kawałki, to taka mapa jest produktem map mniejszych (rys. 2).

Zakłada się, że żaden z krajów pasa rozcinającego sam nie jest pasem rozcinającym. Mapę, która nie jest produktem map mniejszych, pomijając elementy neutralne mnożenia, nazywa się mapą prostą. Mapa prosta nie zawiera pasa rozcinającego $\mathrm{z}$ jednego kraju ani złożonego z dwóch krajów, ani $\mathrm{z}$ trzech. 


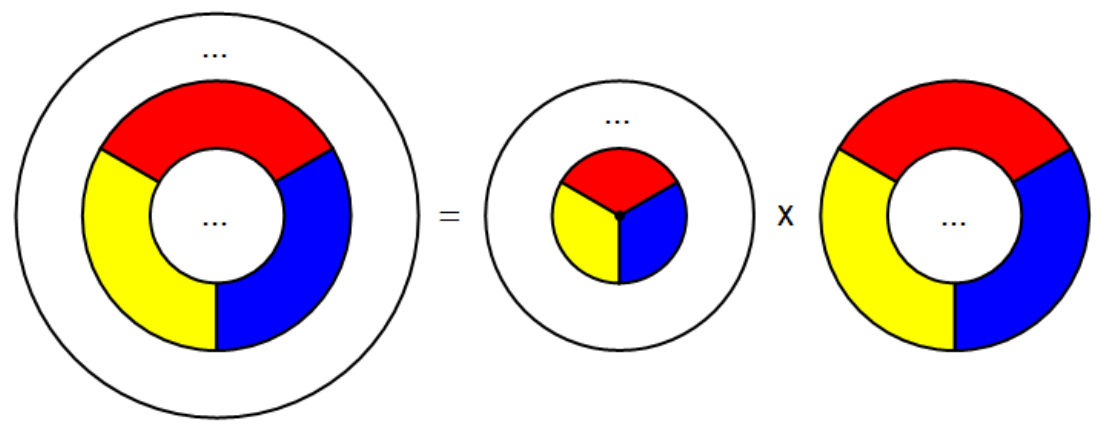

Rys. 2. Iloczyn map

Źródło: opracowanie własne.

Mapa złożona przynajmniej z pięciu krajów, z których jeden jest trójkątem - ma trzy granice, nie jest mapą prostą. Z oczywistych powodów wykluczamy z rozważań mapy, w których występują pierścienie, czyli pasy rozcinające złożone z jednego kraju, a także złożone $z$ dwóch krajów. Nie interesują nas również mapy, w których występują państwa mające tylko trzy granice, czyli państwa będące trójkątami. Wśród pasów rozcinających z trzech krajów wyróżnia się cztery typy:

- pasy typu zerowego, w których kraje są połączone wierzchołkami (rys. 3),

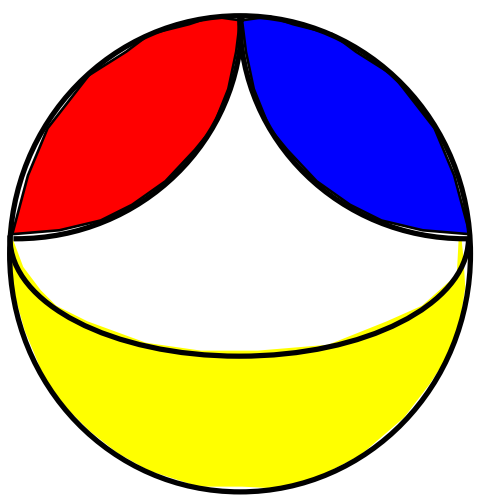

Rys. 3. Pierścień rozcinający typu 0

Źródło: opracowanie własne.

- pasy typu pierwszego, w których są dwa połączenia wierzchołkowe i jedno połączenie linią graniczną (rys. 4), 


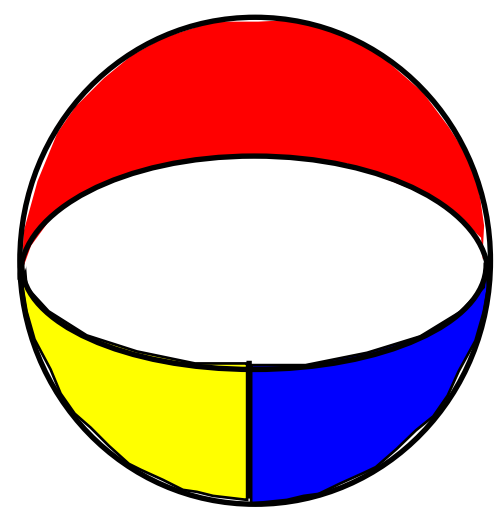

Rys. 4. Pas rozcinający typu 1

Źródło: opracowanie własne.

- pasy typu drugiego, w których jest jedno połączenie wierzchołkowe i dwa krawędziami (rys. 5),

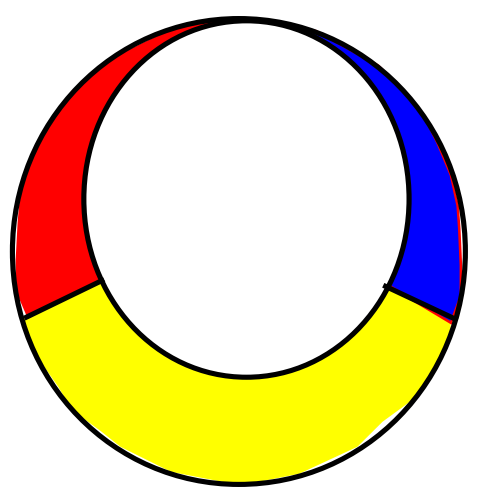

Rys. 5. Pierścień rozcinający typu 2

Źródło: opracowanie własne.

- pasy typu trzeciego, w których wszystkie połączenia są granicami (rys. 1).

Regularyzacja pasa rozcinającego jest operacją zamieniającą wierzchołki łączące kraje na granicy. Mówiąc o iloczynie map, mamy na myśli zawsze pas rozcinający po regularyzacji.

Pasy rozcinające typu zerowego niekiedy wygodnie jest zredukować do jednego państwa. Ułatwia to harmonizację kolorów na różnych czynnikach iloczynu map. Pasy pierwszego typu i pasy drugiego typu można, i czasem 
potrzeba, redukować do pasa rozcinającego złożonego z dwóch krajów. Harmonizacja kolorów sprowadza się do permutacji barw w jednym z czynników produktu. Czynność ta nie zmienia liczby chromatycznej mapy. Lokalnym kolorowaniem jest barwienie zgodne wyłącznie państw stykających się w wierzchołku V. Kolorowanie lokalne nazywa się kolorowaniem minimalnym, jeśli do zgodnego barwienia państw potrzeba użyć dwóch barw lub trzech barw, ale w tym przypadku jednej z nich tylko raz. Istnieją wierzchołki parzyste, w których kolorowanie lokalne zużywa trzy barwy (rys. 6), oraz wierzchołki nieparzyste, w których istnieje kolorowanie lokalne dwiema barwami (rys. 7).

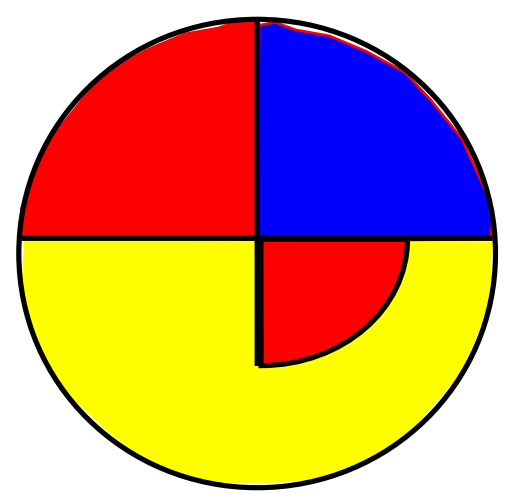

Rys. 6. Wierzchołek parzysty, kolorowanie nieparzyste

Źródło: opracowanie własne.

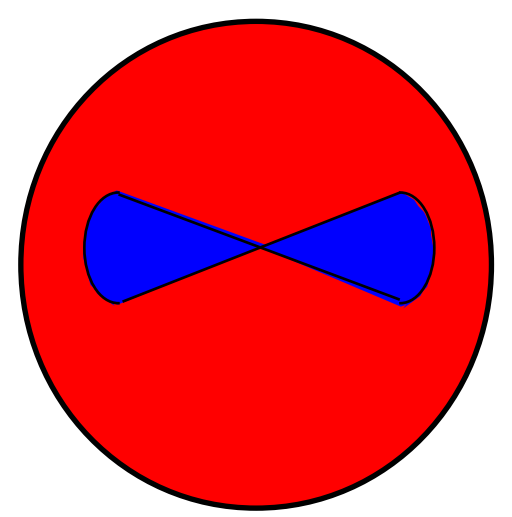

Rys. 7. Wierzchołek nieparzysty, kolorowanie parzyste

Źródło: opracowanie własne. 
Nie w każdym wierzchołku mapy istnieje kolorowanie minimalne (rys. 8).

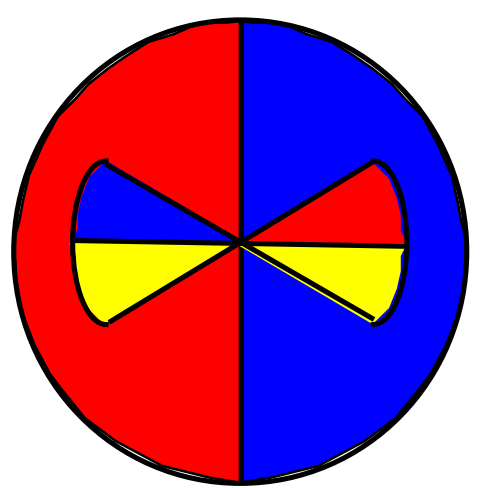

Rys. 8. Wierzchołek bez kolorowania minimalnego

Źródło: opracowanie własne.

Jeśli wierzchołek jest parzysty, to kolorowanie minimalne na mapie prostej jest postaci

lub postaci:

$$
\left(A_{0}, B_{0}, \ldots, A_{r}, B_{r}\right)
$$

$$
\left(A_{0}, B_{0}, \ldots, A_{r}, B_{r}, A_{r+1}, C\right) .
$$

Jeśli wierzchołek jest nieparzysty to kolorowanie minimalne, także na mapie prostej, ma postać:

$$
\left(A_{0}, B_{0}, \ldots, A_{r}, B_{r}, C\right) .
$$

Lemat. Jeśli mapa jest prosta, to w każdym wierzchołku tej mapy istnieje kolorowanie minimalne.

Dowód lematu jest naturalną konsekwencją definicji mapy prostej. Na mapie prostej nie ma bowiem pasów rozcinających utworzonych z jednego kraju lub dwóch krajów, lub trzech krajów. Redukcją mapy nazywa się mapę, która powstaje $\mathrm{z}$ danej mapy przez ściągnięcie jednej granicy do wierzchołka. Po redukcji liczba granic jest mniejsza o jednostkę. Po ściągnięciu, czyli redukcji mapy, wierzchołek, do którego ściągnięto granicę, może zmienić swą parzystość.

Uwaga. Niech liczby naturalne: $k, m, n, s$ spetniaja warunki: $4 \leq k$, $4 \leq m, 7 \leq n$ oraz $0 \leq s \leq 3$. Jeżeli $M=M_{1} \times M_{2}$ oraz mapy: $M, M_{1}, M_{2}$ maja odpowiednio liczbe krawędzi: $n+1, k+3, m+3$, to naturalnie $k+3 \leq n$ oraz $m+3 \leq n$. Jest bowiem $k+s+m=n+1$, gdzie liczba s wskazuje typ pierścienia rozcinającego.

Z uwagi tej korzystamy w dalszym ciągu, nie mówiąc o tym wyraźnie. 
Zasadnicze twierdzenie. Każde kolorowanie minimalne mapy prostej rozszerza się do zgodnego kolorowania całej mapy co najwyżej czterema barwami.

Dowód indukcyjny biegnie względem liczby granic. Zakłada się prawdziwość twierdzenia dla wszystkich map mających $n$ granic, gdzie $n \geq 7$. Niech mapa $M$ ma $n+1$ granic. Jeśli mapa jest prosta, to w wybranym wierzchołku istnieje kolorowanie minimalne. Pokażemy, że rozszerza się ono do kolorowania całej mapy co najwyżej czterema barwami. Ściągamy do wierzchołka $V$ jedną z granic kraju zabarwionego kolorem użytym tylko raz, gdy w kolorowaniu minimalnym występują trzy barwy, lub dowolną granicę, gdy są tylko dwie barwy. Następnie dane kolorowanie minimalne w wierzchołku $V$ rozszerzamy do kolorowania minimalnego w wierzchołku $V$ mapy ściągniętej. Takie rozszerzenie istnieje, bo mapa $M$ z założenia jest prosta. Jeżeli powstała mapa jest prosta, to na podstawie założenia indukcyjnego kolorowanie minimalne rozszerza się do zgodnego barwienia co najwyżej czterema kolorami całej mapy. Po powrocie do stanu przed ściągnięciem otrzymujemy zgodne pokolorowanie wyjściowej mapy co najwyżej czterema barwami. Jeśli zaś ściągnięta mapa nie jest prosta, to jest ona iloczynem map prostych. Wszystkie pasy rozcinające tego iloczynu naturalnie przechodzą przez wierzchołek $V$. Kraje pasa rozcinającego stykające się w wierzchołku $V$ mają zawsze różną naturę; jeden $\mathrm{z}$ nich był pierwotnie $\mathrm{w}$ tym wierzchołku, a drugi przy redukcji mapy został do tego wierzchołka dołączony. Żaden z dwóch krajów leżących przy granicy ściągniętej do punktu nie może wchodzić do pasa rozcinającego. Jeśli pas rozcinający jest postaci $A B X$, gdzie $A$ i $B$ są kolorami użytymi więcej niż raz, a $X$ oznacza kraj leżący poza wierzchołkiem, wtedy $\mathrm{z}$ harmonizacją kolorów map rozciętych tym pasem nie ma problemu. Jeśli zaś pas rozcinający jest postaci $A A X$, wtedy kraj $X$ wciągamy do wierzchołka $V$ i dajemy mu kolor $B$; operacja taka jest dozwolona, ponieważ mapy są proste, więc kraj $X$ nie ma wspólnej granicy z żadnym krajem barwy $B$. Jeśliby kraj $X$ miał wspólną granicę z krajem barwy $B$, to byłby to pas rozcinający, a mapa prosta pasów rozcinających nie ma. Jeśliby natomiast ten układ trzech krajów nie był pasem rozcinającym, wtedy na tej mapie istnieje kraj o trzech granicach. Jest to kraj różny od tych państw, granicę których ściągnięto; takiej sytuacji naturalnie być nie może, bo mapa $M$ nie zawierała kraju o trzech granicach. Oznacza to, że początkowe kolorowanie minimalne mapy przed ściągnięciem rozszerza się do kolorowania zgodnego całej mapy co najwyżej czterema barwami. Dowód twierdzenia został zakończony. 
Wniosek. Każda mape plaska można zgodnie pokolorować co najwyżej czterema barwami - liczba chromatyczna mapy płaskiej nie przekracza czterech.

Wniosek ten natychmiast wynika z udowodnionego wyżej twierdzenia. Jeśli bowiem mapa jest prosta, to nie ma problemu, a gdy nie jest prosta, to rozkłada się ją na produkt map, w którym każdy czynnik ma mniejszą liczbę krawędzi. Z indukcji wynika, że oba czynniki produktu dadzą się pokolorować co najwyżej czterema barwami.

Addendum. Dla kompletu załączamy rysunek pasów rozcinających utworzonych z jednego kraju (rys. 9) oraz pasów rozcinających złożonych z dwóch krajów (rys. 10).
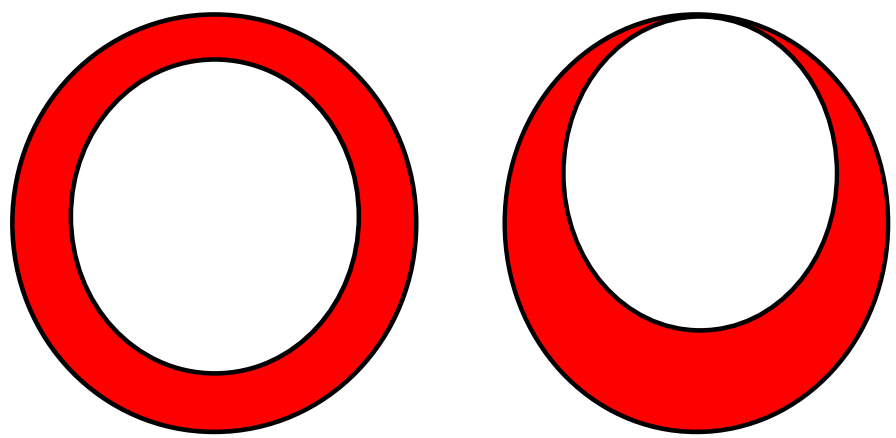

Rys. 9. Pasy rozcinające - jeden kraj

Źródło: opracowanie własne.
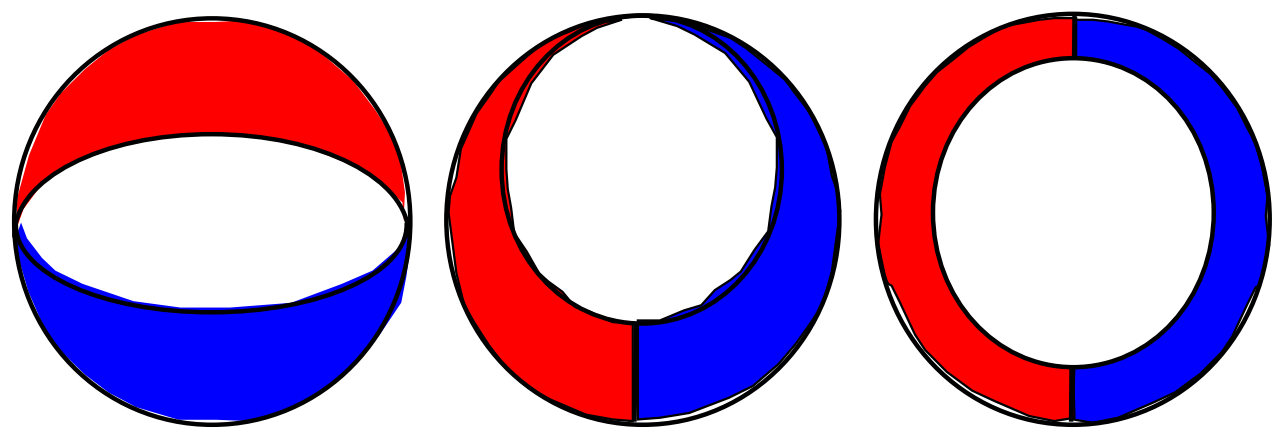

Rys 10. Pasy rozcinające - dwa kraje

Źródło: opracowanie własne. 
Każda mapa będąca powierzchnią wielościanu spełnia wzór Eulera

$$
V-E+F=2 \text {, }
$$

gdzie $V$ oznacza liczbę wierzchołków mapy, $E$ - krawędzi i $F$ - ścian. Mapy leżące na sferze mogą nie spełniać reguły Eulera. Jeżeli mapy $M_{1}$ i $M_{2}$ spełniają regułę Eulera, to ich produkt może już tej zasadzie nie podlegać. Tak jest w przypadku, gdy pomnożymy czworościany, sklejając ich podstawy (rys. 11).

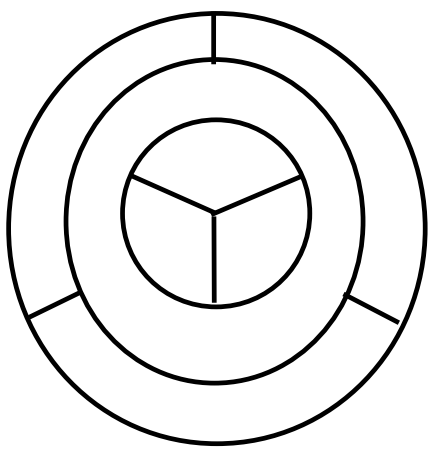

Rys. 11. Unarny produkt czworościanu

Źródło: opracowanie własne.

Każde dwie mapy można pomnożyć, sklejając dwa wybrane kraje. W tym przypadku liczba krajów zmniejsza się o jeden - mamy defekt. Jest to produkt unarny; zamiast wzoru Eulera zachodzi dla mapy $M$ wzór $V-E+F=3$, gdy czynniki produktu spełniają wzór Eulera. Produkt unarny polega na wycięciu kółka w kraju jednej mapy i wybranym kraju drugiej mapy oraz sklejeniu tych map po brzegu wyciętego koła. Jeśli przy mnożeniu map sklejamy dwa kraje na jednej mapie z dwoma krajami na drugiej mapie, a granicę rozdzielającą ich dzielimy na dwie części, wtedy pas rozdzielający jest złożony z dwóch krajów i produkt spełnia wzór Eulera, gdy tylko oba czynniki go spełniały. Jest to produkt binarny. Produkt binarny polega na wycięciu koła na granicy dwóch krajów jednej mapy i podobnego koła na granicy dwóch krajów drugiej mapy, a następnie na sklejeniu brzegów, tak by granice połączyły się. Podobnie jest z produktem map, gdy pas rozcinający złożony jest z trzech krajów; ten iloczyn nazywamy również produktem ternarnym. Mapy można więc mnożyć, a stąd wynika, że można je też pierwiastkować. Dwie mapy są izomorficzne, jeśli istnieje homeomorfizm sfery przyprowadzającej jedną mapę na drugą. 


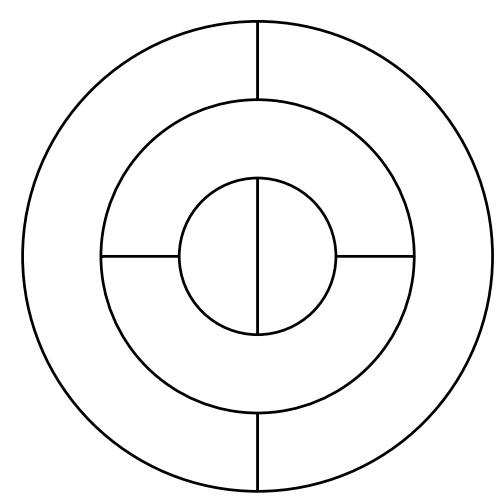

Rys. 12. Kwadrat binarny czworościanu

Źródło: opracowanie własne.

Oczywiście mapa, na której każdy kraj ma trzy granice, jest trójkątem, daje się pokolorować zgodnie co najwyżej czterema barwami; podobnie jest z mapą złożoną co najwyżej z czterech krajów. Jeśli w rodzinie takich map wprowadzimy trzy działania mnożenia wymienione wyżej oraz do tych operacji dołączymy jeszcze ściąganie granicy do punktu i ściąganie kraju do punktu, to otrzymamy rodzinę państw, które dadzą się pokolorować co najwyżej czterema barwami. Podane operacje nie zmieniają własności zgodnego pokolorowania co najwyżej czterema barwami; własność ta jest więc inwariantna ze względu na te operacje.

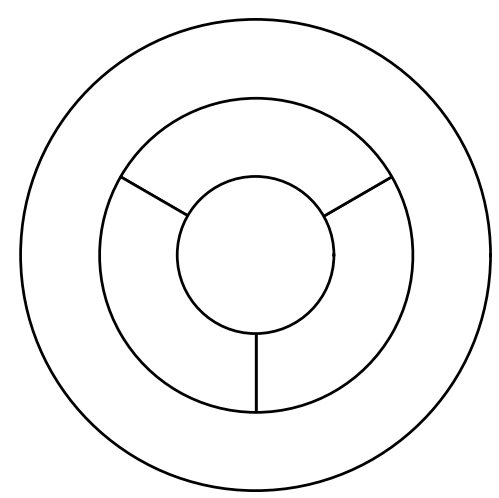

Rys. 13. Kwadrat ternarny czworościanu

Źródło: opracowanie własne. 
Pierwiastkowanie map jest jednoznaczne $\mathrm{z}$ dokładnością do izomorfizmu. Jeśli na mapie istnieje pas rozcinający, złożony z $n$ krajów, to można mówić o produkcie $n$-arnym. Chociaż produkt ten nie zmienia liczby chromatycznej, to jednak nie jest pojęciem użytecznym przy zgodnym barwieniu map co najwyżej czterema barwami. Oznacza to, że jeśli mapa $M$ jest produktem $n$-arnym dwóch map, których liczby chromatyczne nie przekraczają $4 \mathrm{i}$ liczba $n \geq 4$, to nie można a priori twierdzić, że liczba chromatyczna $M$ nie przekracza 4. Nie zawsze niezależne kolorowania czynników produktu dadzą się zharmonizować na pasie rozcinającym, tak aby cała mapa była pokolorowana zgodnie. Istnieją więc pierwiastki kwadratowe $\mathrm{z}$ mapy przy produkcie $n$-arnym. Jeśli mapa $M$ jest produktem $n$-arnym dwóch map i mapa lewa po ściągnięciu do punktu mapy prawej, pomijając pas rozcinający, daje mapę izomorficzną z mapą powstałą z mapy prawej po ściągnięciu do punktu mapy lewej bez pasa rozcinającego, to są one pierwiastkiem z mapy $M$. Dla map płaskich można więc mówić o szukaniu rozwiązania równania $x^{2}=M$ przy różnych produktach. Naturalnie istnieją pierwiastki wyższych stopni z map płaskich.

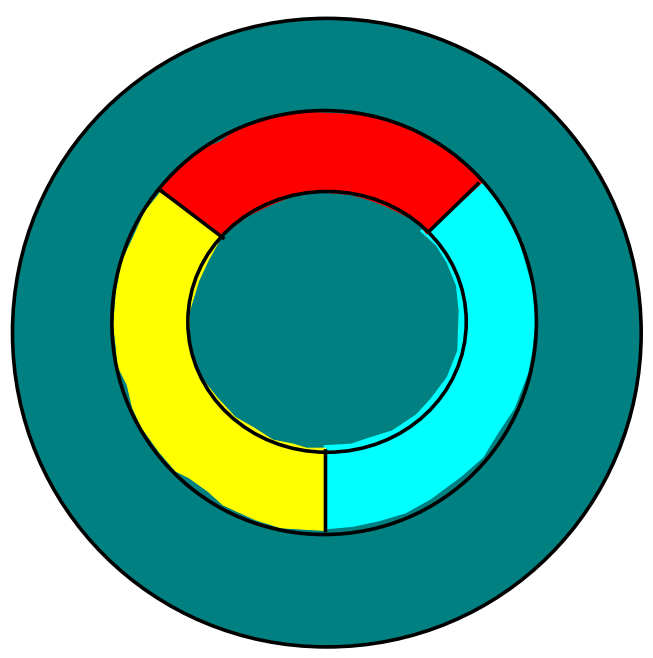

Rys. 14. Ekwiwalentność barwna

Źródło: opracowanie własne. 

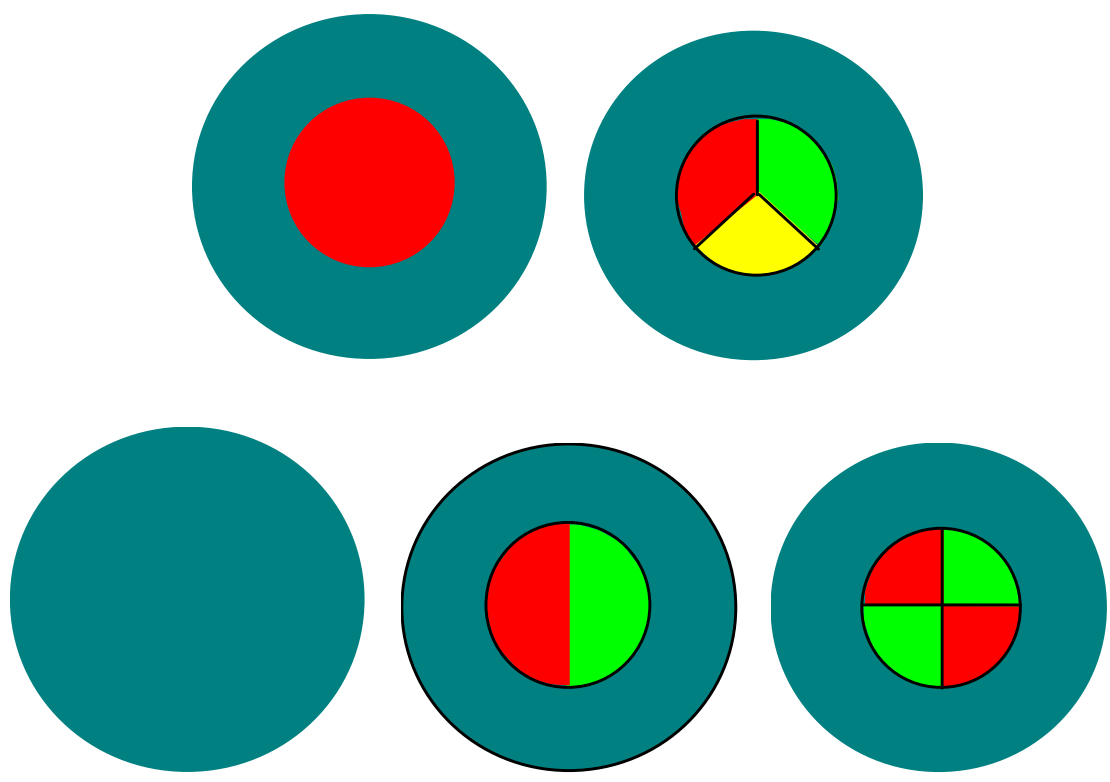

Rys. 15. Mapy atomowe

Źródło: opracowanie własne.

Dwa państwa mapy $M$ są ekwiwalentne barwnie wtedy i tylko wtedy, gdy przy każdym kolorowaniu tej mapy, co najwyżej czterema barwami, państwa te mają tę samą barwę (rys. 14). Oczywiście relacja ta jest ekwiwalentnością w zbiorze państw mapy $M$. Jeżeli 2 kraje mają wspólny wierzchołek, to nie są one ekwiwalentne pod względem barwy. Hipoteza ta jest równoważna hipotezie, że liczba chromatyczna każdej mapy płaskiej nie przekracza 4.

$\mathrm{W}$ rodzinie map płaskich istnieją mapy proste, zwane dalej mapami atomowymi, z których daje się utworzyć każdą mapę. Mapy atomowe są więc jakby literami, z których buduje się większe mapy - słowa (rys. 15). Mapy atomowe oznaczamy symbolem $M_{1}$, gdzie $n$ jest dowolną liczbą naturalną. Indeks 1 oznacza południową półkulę mapy, a $n$ wskazuje na ile krajów podzielona jest sfera północna. Jeżeli $n$ jest 0 , to liczba chromatyczna mapy $M_{10}$ jest naturalnie 1 . Jeżeli $n$ jest liczbą parzystą $\geq 2$, to liczba chromatyczna mapy atomowej to 3 , a gdy $n$ jest 1 , to liczbą chromatyczną mapy $M_{11}$ jest 2 . Jeśli natomiast $n$ jest liczbą nieparzystą $\geq 3$, to liczbą chromatyczną mapy atomowej jest 4 .

Problem czterech barw jest stary i trudny. Ciągle nie ma krótkiego i powszechnie uznanego dowodu twierdzenia, że liczba chromatyczna każdej mapy płaskiej nie przekracza czterech. Na problem kolorowania map można 
spojrzeć jak na zagadnienie równoważności słów w określonej półgrupie. Niech $M$ oznacza rodzinę wszystkich map płaskich. Dwie mapy utożsamia się, jeśli istnieje homeomorfizm sfery przeprowadzający jedną z nich na drugą. Terminy „mapy płaskie” i „mapy sferyczne” są synonimami. Niech dalej $X$ oznacza wszystkie mapy płaskie, których liczba chromatyczna nie przekracza czterech, wreszcie $P$ niech będzie rodziną wszystkich map prostych [Smoluk 2016]. Rodzina map $M$ jest uogólnioną grupą słów w alfabecie $P$. Jest to uogólniona półgrupa, bo jest w niej kilka elementów neutralnych, a ponadto mapy sferyczne, to słowa przestrzenne - dopisywać słowo do słowa można $\mathrm{z}$ różnych stron, a nie tylko z lewej czy prawej. Prosty lemat mówi, że $X$ jest uogólnioną półgrupą w półgrupie $M$. Główny ciężar dowodu o czterech barwach sprowadza się do pokazania inkluzji $P \subseteq X$, czyli do pokazania, że każda mapa prosta koloruje się zgodnie co najwyżej czterema barwami. Prosty wniosek z tych dwóch faktów jest twierdzeniem o czterech barwach. Jeżeli bowiem $M \in M$, to albo $M \in P$, albo $M=M_{1} \times M_{2}$, gdzie $M_{1}$, $\mathrm{M}_{2} \in X$; zawsze więc $\mathrm{M} \in X$, czyli $X=M$. Każda mapa płaska ma liczbę chromatyczną nieprzekraczającą 4. Półgrupa słów upraszcza istotnie dowód twierdzenia odpornego na inne metody.

Doktorom Arkadiuszowi Maciukowi (rys. 2, 12, 13) oraz Czesławowi Szmiglowi (pozostałe) dziękuję za rysunki.

\section{Literatura}

Appel K., Haken W. (1976). Every planar map is four colorable. Bulletin of the American Mathematical Society. Vol. 82. S. 711,712.

Smoluk A. (2016). A simple proof of the four-colors theorem. Didactics of Mathematics. Nr 13 (17). Wydawnictwo Uniwersytetu Ekonomicznego we Wrocławiu. S. 35-38.

Smoluk A. (2017). Prosty dowód twierdzenia o czterech barwach. Ekonometria. Nr 55. Wydawnictwo Uniwersytetu Ekonomicznego we Wrocławiu. S. 21-24. 